\title{
Life Cycle Labor Supply and Panel Data: A Survey
}

\author{
Bertrand Koebel, François Laisney, Winfried Pohlmeier and Matthias Staat
}

\section{Introduction}

The econometrics of labor supply belongs to one of the technically most advanced fields in microeconometrics. Many specific issues such as the proper modelling of tax structures, the existence of fixed costs as well as rationing have been treated in numerous articles so that marginal gains in substantive economic insights seem low and entry costs into the field prohibitively high. Not surprisingly, one of the most obvious paths for research on labor supply, the (micro-) econometric analysis of the individual's labor supply over the life cycle, has by now gained much more attention than 10 years ago. The increased availability of panel data for many countries, as well as the development of appropriate econometric techniques, have made econometric studies of intertemporal labor supply behavior using panel data not only interesting on purely theoretical grounds, they have also helped to achieve a better understanding of individual retirement behavior, the functioning of institutional settings in different countries (such as taxes, vocational training programmes, day-care for children) and the distribution of income and wealth, to name only a few.

Estimation of labor supply functions using panel data has started out in the eighties, and the number of studies reporting on such estimation is rapidly increasing.

\section{Bertrand Koebel}

BETA, Université Louis Pasteur, Strasbourg I and IZA, Bonn, 61 Avenue de la Forêt Noire, F67000 Strasbourg, France, e-mail: koebel@ cournot.u-strasbg.fr

François Laisney

BETA, Université Louis Pasteur, Strasbourg I and ZEW, Mannheim, 61 Avenue de la Forêt Noire, F67000 Strasbourg, France, e-mail: fla@cournot.u-strasbg.fr

Winfried Pohlmeier

University of Konstanz, Department of Economics, Box D124, D78457 Konstanz, Germany, e-mail: winfried.pohlmeier@uni-konstanz.de

Matthias Staat

University of Mannheim, Department of Economics, D68131 Mannheim, Germany, e-mail: matthias@pool.uni-mannheim.de 
Earlier studies using panel data mainly concentrated on participation. Thus, it is not surprising that the excellent surveys of Pencavel (1986), Heckman and MaCurdy (1986) and Killingsworth and Heckman (1986) hardly touched the subject. ${ }^{1}$ The latter survey concluded a comparison of a large number of cross section studies with the words: "[these studies] seem to have reduced the mean and substantially increased the variance of [...] what might be called the reasonable guesstimate of the wage elasticity of female labour supply [...]. ${ }^{2}$ However, [...] studies based on alternative behavioural models_-notably, life cycle models, which have been used relatively little in empirical studies - are also likely to provide important insights" (pp. 196-197).

Earlier surveys of some of the material covered here can be found in Blundell (1987, 1988), Blundell, Fry and Meghir (1990), Card (1994), MaCurdy et al. (1990) and Blundell and MaCurdy (1999).

As we shall see, there has been a trend away from models that take advantage of panel data almost exclusively in order to control for unobserved heterogeneity, towards fully dynamic models where wages become endogenous, and consequently the concept of wage elasticity loses much of its appeal.

This chapter aims at providing the reader with a thread through the literature on the topic. However, we make no claim to exhaustivity, and concentrate mainly on the theoretical aspects of the studies. In Sect. 23.2 we describe the basic model of life cycle $\lambda$-constant labor supply. Sect. 23.3 is devoted to extensions taking account of uncertainty and risk, while Sect. 23.4 discusses voluntary and involuntary nonparticipation, as well as accounting for taxation. Sect. 23.5 presents an alternative specification which leaves the $\lambda$-constant framework, and discusses its implications, in particular for modelling the impact of taxes on labor supply. In Sect. 23.6 we discuss studies relaxing within-period and between-period additive separability, and focusing on rational habit formation and human capital accumulation. Sect. 23.7 concludes and opens towards other strands of the literature that contribute to the understanding of labor supply.

\subsection{The Basic Model of Life Cycle Labor Supply}

We shall not restate here the theoretical developments contained in the survey of Killingsworth and Heckman (1986) (pp. 144-179) but refer the reader to them. Killingsworth and Heckman insist on the pioneering work of Mincer (1962). They show that "the distinction between permanent and transitory wages is not particularly useful from a theoretical standpoint" (p. 158) and demonstrate the usefulness of Frisch demands as an alternative to the permanent vs. transitory distinction. ${ }^{3}$ They also discuss models with endogenous wages and conclude: "although much informal discussion implicitly or explicitly emphasizes the interrelationships be-

\footnotetext{
${ }^{1}$ Yet see Chap. 5 in Killingsworth (1983), pp. 207-330.

${ }^{2}$ Here we shall not restrict attention to female labor supply.

${ }^{3}$ The uninformed reader will find a definition below.
} 
tween (...) work and wages in a life-cycle setting, rigorous analysis of such issues using formal life-cycle labour supply models with endogenous wages is still in its infancy" (p. 178). Here we will describe the models used for estimation in a selection of papers representative of the trend over the last 25 years. Along the way we also give some details on the estimation techniques and on the results, illustrating the fact that econometric modelling is by no means linear: there is a feedback of estimation results on model specification.

\subsubsection{The Framework}

The seminal paper, as far as empirically implementable models are concerned, is MaCurdy (1981). ${ }^{4}$ The assumptions retained are fairly stringent and include known life length $T$, perfect foresight and perfect credit markets, as well as rates of time preference that may differ across individuals and do not change over time. At time 1 an individual chooses $\left\{C_{i t}, L_{i t}, A_{i t}\right\}_{t=1}^{T}$ in order to maximizes discounted utility

$$
\sum_{t=1}^{T} \frac{1}{\left(1+\rho_{i}\right)^{t-1}} U_{i t}\left(C_{i t}, L_{i t}\right)
$$

subject to the sequence of budget constraints

$$
A_{i t}=\left(1+r_{t}\right) A_{i, t-1}+w_{i t} N_{i t}-C_{i t}, \quad t=1, \ldots, T .
$$

The variable $C$ denotes real consumption, $L$ leisure, $A$ end of period assets in real terms, $N$ hours of work $(N=\bar{L}-L$, where $\bar{L}$ denotes maximum time available in each period for allocation between leisure and market work), $r$ is the real interest rate, $w$ the real wage, $\rho$ the rate of time preference, and $A_{0}$ denotes initial assets. The within-period utility function $U_{i t}$ is assumed to be concave.

The first-order conditions, assuming an interior optimum, include the budget restrictions (23.2) and

$$
\begin{aligned}
& \frac{\partial U_{i t}}{\partial C_{i t}}=\lambda_{i t}, \\
& \frac{\partial U_{i t}}{\partial L_{i t}}=\lambda_{i t} w_{i t}, \quad t=1, \ldots, T,
\end{aligned}
$$

where $\lambda_{i t}$ denotes the Lagrange multiplier of the budget constraint in period $t$. Notice that (pseudo) optimal demands can be derived by solving (23.2)-(23.4), eliminating $\lambda_{i t}$, to obtain $\widetilde{C}_{i t}\left(S_{i t}, w_{i t}\right), \widetilde{L}_{i t}\left(S_{i t}, w_{i t}\right)$, where $S_{i t} \equiv A_{i t}-\left(1+r_{t}\right) A_{i, t-1}$ denotes the level of saving or dissaving. ${ }^{5}$ In the timewise additive separable case, net saving $S_{i t}$ is a sufficient statistic of all the future as far as the present decision is concerned. In

\footnotetext{
${ }^{4}$ For the purpose of comparability with later sections, we slightly depart from MaCurdy's exposition and notations.

${ }^{5}$ MaCurdy (1983, p.271) calls $\widetilde{C}$ and $\widetilde{L}$ pseudo demand functions.
} 
general, the argument $S_{i t}$ of functions $\widetilde{C}_{i t}$ and $\widetilde{L}_{i t}$ will not be arbitrary, but optimally chosen by individuals. For this reason it will depend of the entire wage profile, of the initial wealth $A_{i 0}$ and of the interest and time preference rates. This functional dependence in general implies correlation between $S_{i t}$ and the past and future variables, and shocks and thus calls for instrumental variable estimation methods.

Instead of considering $\widetilde{C}$ and $\widetilde{L}$, MaCurdy (1981) derives the Frisch demands $C_{i t}\left(\lambda_{i t}, w_{i t}\right), L_{i t}\left(\lambda_{i t}, w_{i t}\right)$, obtained by solving (23.3)-(23.4). The Lagrange multiplier $\lambda_{i t}$ measures the impact of a marginal increase in $A_{i t}$ on the optimal value of objective (23.1). From the envelope theorem, we have

$$
\lambda_{i t}=\frac{1+r_{t+1}}{1+\rho_{i}} \lambda_{i t+1},
$$

or, using a first-order approximation around $\rho_{i}=r_{t+1}=0$,

$$
\ln \lambda_{i t} \approx r_{t+1}-\rho_{i}+\ln \lambda_{i, t+1}
$$

The value of $\lambda_{i t}$ is implicitly determined by substitution of the demand functions $C$ and $L$ in (23.2). Thus, $\lambda_{i t}$ is a function of the entire wage profile, of the initial wealth $A_{i 0}$ and of the interest and time preference rates $r_{t}$ and $\rho_{i}$. Just as $S_{i t}, \lambda_{i t}$ is a sufficient statistic which summarizes the impact of all the future variables on the present decision. As before, the use of instrumental variables is recommended for parameter estimation. Using (23.5) and (23.6), we can write

$$
\lambda_{i t}=\lambda_{i 0} \prod_{k=1}^{t} \frac{1+\rho_{i}}{1+r_{k}}
$$

or, assuming small values for $\rho_{i}$ and the $r_{k}$,

$$
\ln \lambda_{i t} \approx t \rho_{i}-R_{t}+\ln \lambda_{i 0}
$$

where $R_{t}=\sum_{k=1}^{t} r_{k}$, and substitute this term into functions $C$ and $L$ to obtain

$$
C_{i t}^{*}\left(w_{i t}, \lambda_{i 0}\right) \text { and } L_{i t}^{*}\left(w_{i t}, \lambda_{i 0}\right) .
$$

The concavity of $U_{i t}$ implies

$$
\begin{aligned}
& \frac{\partial C_{i t}^{*}}{\partial w_{i t}} \geq 0, \quad \frac{\partial L_{i t}^{*}}{\partial w_{i t}} \leq 0, \\
& \frac{\partial C_{i t}^{*}}{\partial \lambda_{i 0}} \leq 0, \quad \frac{\partial L_{i t}^{*}}{\partial \lambda_{i 0}} \leq 0, \quad \frac{\partial^{2} L_{i t}^{*}}{\partial \lambda_{i 0}^{2}} \leq 0, \\
& \text { and } \quad \frac{\partial \lambda_{i 0}^{*}}{\partial A_{i 0}} \leq 0, \quad \frac{\partial \lambda_{i 0}^{*}}{\partial w_{i t}} \leq 0, \quad t=1, \ldots, T \text {. }
\end{aligned}
$$

where $\lambda_{i 0}^{*}\left(\left\{w_{i t}\right\}_{t=0}^{T}, A_{i 0}\right)$ is the value of the multiplier corresponding to the optimal solution. 
Both types of demand functions are related by:

$$
L^{*}\left(\lambda_{i 0}^{*}, w_{i t}\right)=\widetilde{L}\left(S_{i 0}, w_{i t}\right) .
$$

Two measures have focused the interest of economists: the Frisch elasticity of labor supply with respect to the wage, denoting $N_{i t}^{*}=N^{*}\left(\lambda_{i 0}, w_{i t}\right)$,

$$
e_{\lambda} \equiv \frac{\partial N_{i t}^{*}}{\partial w_{i t}} \frac{w_{i t}}{N_{i t}^{*}},
$$

and the intertemporal elasticity of substitution between labor supplies of two consecutive periods:

$$
i e s \equiv \frac{\partial\left(N_{i t}^{*} / N_{i, t+1}^{*}\right)}{\partial\left(w_{i t} / w_{i, t+1}\right)} \frac{w_{i t} / w_{i, t+1}}{N_{i t}^{*} / N_{i, t+1}},
$$

which gives the inverse of the percentage change in the relative labor supplies (of two consecutive periods), when the ratio of relative wages $w_{i t} / w_{i, t+1}$ increases by $1 \%$.

\subsubsection{First Specifications of the Utility Function}

MaCurdy (1981) specifies the following additively separable within-period utility function for individual $i$ :

$$
U_{i t}\left(C_{i t}, L_{i t}\right)=\gamma_{C i t} C_{i t}^{\beta}-\gamma_{N i t} N_{i t}^{\alpha_{N}}, \quad\left[N_{i t}=\bar{L}-L_{i t}\right], \quad i=1, \ldots, I .
$$

Concavity requires $0<\beta<1, \alpha_{N}>1$. Heterogeneity, both observed and unobserved, is modelled through random preferences with the specification

$$
\ln \gamma_{N i t}=\sigma_{i}-u_{i t}^{*}
$$

where $u_{i t}^{*}$ is i.i.d. with zero expectation (note that time-varying characteristics are excluded by assumption).

The resulting Frisch labor supply and consumption demand equations are:

$$
\begin{aligned}
& \ln N_{i t}=\frac{1}{\alpha_{N}-1}\left(\ln \lambda_{i t}-\ln \alpha_{N}+\ln w_{i t}-\sigma_{i}+u_{i t}^{*}\right) \\
& \ln C_{i t}=\frac{1}{\beta-1}\left(\ln \lambda_{i t}-\ln \gamma_{C i t}-\ln \beta\right) .
\end{aligned}
$$

Using (23.8), we obtain (assuming $\rho_{i}=\rho$ )

$$
\ln N_{i t}=F_{i}+b t-\delta R_{t}+\delta \ln w_{i t}+u_{i t}
$$


with

$$
F_{i}=\frac{1}{\alpha_{N}-1}\left(\ln \lambda_{i 0}-\sigma_{i}-\ln \alpha_{N}\right), \quad \delta=\frac{1}{\alpha_{N}-1}, \quad b=\delta \rho, \quad u_{i t}=-\delta u_{i t}^{*} .
$$

This is a linear panel model with an individual-specific effect $F_{i}$, which has to be treated as a fixed effect because it is correlated with $w_{i t}$ via $\lambda_{i 0}$. Notice that when the $\rho_{i}$ are not all identical, there is in addition heterogeneity in the parameter $b$. In this model, the Frisch elasticity of labor supply is given by $\delta=1 /\left(\alpha_{N}-1\right)$ and is also equal to the intertemporal elasticity of substitution.

Moreover, MaCurdy considers the following linear approximation of $F_{i}$ :

$$
F_{i}=Z_{i} \phi+\sum_{t=1}^{T} \gamma_{t} \ln w_{i t}+A_{i 0} \theta+\alpha_{i}
$$

where $Z_{i}$ denotes a vector of household characteristics and $\alpha_{i}$ a residual term. According to (23.9), $\gamma_{t}$ and $\theta$ should be negative. Note that coefficients are identical across households. Combined with the additional assumption of a quadratic form for the profile of log wages,

$$
\ln w_{i t}=\pi_{0 i}+\pi_{1 i} t+\pi_{2 i} t^{2}+\xi_{i t},
$$

this leads to

$$
F_{i}=Z_{i} \phi+\pi_{0 i} \bar{\gamma}_{0}+\pi_{1 i} \bar{\gamma}_{1}+\pi_{2 i} \bar{\gamma}_{2}+A_{i 0} \theta+\eta_{i}
$$

with

$$
\bar{\gamma}_{j}=\sum_{t=1}^{T} \gamma_{t} t^{j}, \quad j=0,1,2
$$

Interpretation: $\delta$ is the intertemporal substitution (or $\lambda$-constant, or Frisch) elasticity. It describes the reaction to an evolutionary change of the wage rate along the wage profile. It is positive since $\alpha_{N}>1$. Along a profile, evolutionary changes take place. MaCurdy calls changes between profiles parametric or profile changes. A change $\Delta>0$ from a wage profile I to an otherwise identical profile II at time $s$ causes the Frisch labor supply of profile II to be lower than that of profile I in all periods $t \neq s$, because $\lambda_{I I}<\lambda_{I}$ by (23.9). Equation (23.14) implies

$$
F_{I I}-F_{I}=\gamma_{s} \Delta<0
$$

The net effect on labor supply in period $s,\left(\delta+\gamma_{s}\right) \Delta$, can be positive or negative. $\delta+$ $\gamma_{s}$ and $\gamma_{s}$ are the usual uncompensated (own- and cross-period) elasticities, and the corresponding compensated elasticities are $\delta+\gamma_{s}-\mathrm{E}_{s} \theta$ and $\gamma_{s}-\mathrm{E}_{s} \theta$, respectively, where $\mathrm{E}_{s}$ denotes real earnings in period $s$. If leisure is a normal $\operatorname{good}(\theta<0)$, we have

$$
\delta>\delta+\gamma_{s}-\mathrm{E}_{s} \theta>\delta+\gamma_{s}
$$

i.e.

$$
e_{\lambda}>e_{u}>e_{A}
$$


where $e_{\lambda}$ is the wage elasticity with constant marginal utility of wealth, $e_{A}$ is the wage elasticity with constant (lifetime) wealth and $e_{u}$ is the wage elasticity with constant (lifetime) utility. Bover (1989) and Blundell, Meghir and Neves (1993) give useful discussions of the relationships between these elasticities.

Estimation is conducted in two stages.

Stage 1: (23.12) is estimated in first differences: ${ }^{6}$

$$
\Delta \ln N_{i t}=b-\delta r_{t+1}+\delta \Delta \ln w_{i t}+\varepsilon_{i t}, \quad t=2, \ldots, \tau, \quad i=1, \ldots, I .
$$

MaCurdy (1981) considers the Frisch labor supply equations across the $\tau$ available time periods as a system. No restrictions are imposed on the temporal covariance structure of $\varepsilon$. As the level of wages may depend upon unobserved individual characteristics which also affect the amount of working time, the variable $w_{i t}$ can be suspected to be correlated with $\varepsilon_{i t}$. MaCurdy uses system estimation (2SLS and 3SLS), and treats $\ln w_{i t}$ as endogenous, with instruments derived from a human capital type equation.

In this way, the reactions of $N_{i t}$ to the evolutionary changes in $w_{i t}$ are completely described by $\widehat{\delta}$. In order to also describe the reactions of labor supply to parametric changes in wages, information on the sensitivity of $F_{i}$ with respect to $w_{i t}$ is needed.

Stage 2: Given the first stage parameter estimates, the fixed effects can be estimated using (23.12) as:

$$
\hat{F}_{i}=\frac{1}{\tau} \sum_{t=1}^{\tau}\left(\ln N_{i t}-\hat{b} t+\hat{\delta} R_{t}-\hat{\delta} \ln w_{i t}\right) .
$$

A similar method is used to obtain estimates of the $\pi_{h i}$ parameters, which then allows to estimate the unknown parameter of (23.16). These estimates can then be used to identify the labor demand reaction to a shift in the wage profile and to obtain an estimate of the wage elasticity $e_{A}$.

Note that there are also contributions estimating pseudo supply functions. For instance, Conway and Kniesner (1994) consider the following econometric specification:

$$
N_{i t}=F_{i}+\delta w_{i t}+\kappa S_{i t}+Z_{i t} \pi+u_{i t},
$$

which is a linear pseudo labor function (depending upon savings), where variables $w_{i t}$ and/or $S_{i t}$ are allowed to be correlated with the random term $u_{i t}$ and individual specific heterogeneity $F_{i}$. They use a sample of prime aged men from the PSID who worked each year from 1978 to 1982 and experiment with different types of instruments. They find that pseudo labor supply is decreasing in the wage in 59 out of the 60 regressions considered. This finding is at odds with (23.9).

\footnotetext{
${ }^{6}$ Henceforth, $\Delta$ will denote the first difference operator. Another possibility would be to use within estimation. One advantage of estimation in first differences, however, is that no strict exogeneity assumption is needed.
} 


\subsection{Taking Account of Uncertainty and Risk}

So far we have only considered labor substitution over time, which measures changes in labor supply in response to anticipated wage changes. How individuals react in response to unanticipated wage and interest rate changes is important to better understand the labor market impacts of monetary and fiscal policies for example. The labor market implications of wage and interest rate volatility may also have consequences for the optimal design of labor contracts and the organization of financial markets.

MaCurdy (1983) was the first to propose an empirical framework allowing to cope with uncertainty. He showed that uncertainty concerning wages and interest rates can be accounted for by slightly adapting the model with certainty, so that most uncertainty can be summarized into an additive residual term. The use of adequate instruments then allows to consistently estimate the parameters of interest. Some 20 years later, Pistaferri (2003) showed that a more precise modelling of uncertainty yields a different specification of labor supply relationships. This allows economists to study how labor supply reacts to unanticipated changes not only in wages and interest rates, but also in other dimensions like wealth or family composition. As soon as uncertainty is introduced in the model, risk also naturally arises in the specification of labor supply. Lich-Tyler (2002) investigated this second issue. Both topics are related and can be presented within a comprehensive framework.

\subsubsection{First Developments}

Following MaCurdy (1983), we assume uncertainty concerning future wages and interest rates. Replanning for the future takes place in every period, on the basis of the new information obtained. The individual maximizes expected discounted utility in period $t$ :

$$
\mathrm{E}_{t} \sum_{s=t}^{T} \frac{1}{\left(1+\rho_{i}\right)^{s-t}} U_{i s}\left(C_{i s}, L_{i s}\right),
$$

subject to the budget restriction (23.2). If we exclude corner solutions, the first-order conditions include (23.3) and (23.4) at period $t=1$.

As in static models, the ratio of first derivatives is still equal to relative prices, so that this can provide the basis for estimating demand elasticities. This estimation strategy was followed by MaCurdy (1983), using instrumental variables for controlling the endogeneity of $C_{i t}$ and $L_{i t}$. Note that also the functions $C_{i t}^{*}$ and $L_{i t}^{*}$ are just the same as in the certain case. This might suggest that differences between the certain and uncertain cases are not important in the time additive separable case. However, the level of saving $S_{i t}$ chosen in period $t$ for some configuration of expected future wage and interest rate paths, can turn out not having been optimal ex post, once time discloses additional information. This is why replanning is necessary at each period. 
The Lagrange multipliers now satisfy

$$
\lambda_{i t}=\mathrm{E}_{t}\left(\frac{1+r_{t+1}}{1+\rho_{i}} \lambda_{i, t+1}\right),
$$

implying that the individual decides on savings in such a way that the discounted expected utility of wealth remains constant. If we assume that there is no uncertainty about $r_{t+1}$ we have

$$
\lambda_{i t}=\frac{1+r_{t+1}}{1+\rho_{i}} \mathrm{E}_{t} \lambda_{i, t+1},
$$

which leads to the (first-order) approximation

$$
\begin{aligned}
\ln \lambda_{i t} & \approx \mathrm{E}_{t} \ln \lambda_{i, t+1}-\rho_{i}+r_{t+1} \\
& =\ln \lambda_{i, t+1}-\rho_{i}+r_{t+1}+e_{i, t+1},
\end{aligned}
$$

where the random term $e_{i, t+1}$, a forecast error of the marginal utility of next period, satisfies $\mathrm{E}_{t}\left(e_{i, t+1}\right)=0$. Once substituted in the $\lambda$-constant demands in first difference obtained from (23.12):

$$
\Delta \ln N_{i t} \approx \delta \Delta \ln w_{i t}+\delta\left(\ln \lambda_{i, t+1}-\ln \lambda_{i t}\right),
$$

this yields

$$
\Delta \ln N_{i t} \approx \delta \Delta \ln w_{i t}+\delta\left(\rho_{i}-r_{t+1}\right)-\delta e_{t+1} .
$$

From (23.19) and the expression $N\left(\lambda_{i t}, w_{i t}\right)$ of Frisch labor supply, it can be seen that expected changes in $\lambda_{i, t+1}$ are already taken into account for determining labor supply at period $t$. As a consequence, only unexpected changes in the marginal utility of wealth influence changes in labor supply through $e_{i, t+1}$. This is the economic interpretation of the residual term in (23.22).

As in the certain case, the $\lambda$-constant demands can be relied on for estimation. The "fixed effects" techniques remain available in the presence of uncertainty about the wage profile. Under rational expectations, the orthogonality between $e_{i, t+1}$ and the information available at time $t$ suggests application of the Generalized Method of Moments (GMM). Exposition here has been kept fairly sketchy, and we refer the reader to Altug and Miller (1990) for a more elaborate treatment spelling out the implications of assuming a competitive environment with complete markets.

Others contributions in this vein investigate the impact of unexpected capital, windfall gains, house price shocks and inheritance on labor supply: see Joulfaian and Wilhelm (1994) and Henley (2004). Both studies report that unexpected gains exert (mostly) significant negative effects on working hours, but their impact is relatively small in absolute value. 


\subsubsection{Recent Contributions}

Now we turn to the contributions of Pistaferri (2003) and Lich-Tyler (2002), who derive a labor supply specification from a more precise approximation of the relationship between consecutive marginal utilities of wealth (23.19). Although we do not follow exactly each author's presentation, we hope that our interpretation does a good job of summarizing the main novelty of both contributions.

Without (intra-period) additive separability between consumption and leisure (see next section), the $\lambda$-constant demands in first differences (23.21) become

$$
\Delta \ln N_{i t} \approx \delta \Delta \ln w_{i t}+\eta\left(\ln \lambda_{i, t+1}-\ln \lambda_{i t}\right),
$$

where $\eta>\delta$ when $C$ and $L$ are substitutes and $\eta<\delta$ when they are complements. Instead of approximating $\ln \lambda_{i t}$ by (23.20), let us use a second order Taylor approximation to the random function $\lambda_{t+1}\left(1+r_{t+1}\right) /(1+\rho)$ in the neighborhood of its arguments' mean and take its expectation to obtain

$$
\begin{aligned}
\ln \lambda_{i t} & \approx \ln \left[\frac{1+\mathrm{E}_{t} r_{t+1}}{1+\rho} \mathrm{E}_{t} \lambda_{i, t+1}\right] \\
& +\frac{1}{2(1+\rho)} \mathrm{E}_{t}\left(\begin{array}{c}
r_{t+1}-\mathrm{E}_{t}\left(r_{t+1}\right) \\
\lambda_{i, t+1}-\mathrm{E}_{t}\left(\lambda_{i, t+1}\right)
\end{array}\right)^{\prime}\left(\begin{array}{ll}
0 & 1 \\
1 & 0
\end{array}\right)\left(\begin{array}{c}
r_{t+1}-\mathrm{E}\left(r_{t+1}\right) \\
\lambda_{i, t+1}-\mathrm{E}\left(\lambda_{i, t+1}\right)
\end{array}\right) \\
& \approx \ln \mathrm{E}_{t} \lambda_{i, t+1}-\rho+\mathrm{E}_{t} r_{t+1}+\frac{\operatorname{Cov}_{t}\left(r_{t+1}, \lambda_{i, t+1}\right)}{(1+\rho)}
\end{aligned}
$$

Similarly, it can be shown that: ${ }^{7}$

$$
\mathrm{E}_{t} \ln \lambda_{i, t+1} \approx \ln \mathrm{E}_{t} \lambda_{i, t+1}-\frac{\operatorname{Var}_{t}\left(\lambda_{i, t+1}\right)}{2\left(\mathrm{E}_{t} \lambda_{i, t+1}\right)^{2}}
$$

Replacing these expressions into (23.23) yields

$$
\begin{aligned}
\Delta \ln N_{i t} \approx \eta\left(\rho-r_{t+1}\right)+\delta \Delta \ln w_{i t}+\eta\left(r_{t+1}-\mathrm{E}_{t} r_{t+1}-\frac{1}{1+\rho} \operatorname{Cov}_{t}\left(r_{t+1}, \lambda_{i, t+1}\right)\right) \\
+\eta\left(\ln \lambda_{i, t+1}-\mathrm{E}_{t} \ln \lambda_{i, t+1}-\frac{\operatorname{Var}_{t}\left(\lambda_{i, t+1}\right)}{2\left(\mathrm{E}_{t} \lambda_{i, t+1}\right)^{2}}\right)
\end{aligned}
$$

This is the extended $\lambda$-constant labor supply relationship which depends on two new kinds of explanatory variables: (i) innovations in the marginal utility of wealth and interest rate, and (ii) risk in the marginal utility of wealth and interest rate, reflected in the variance-covariance terms. An increase in $\operatorname{Var}_{t}\left(\lambda_{i, t+1}\right)$ has the same effect as reducing the marginal utility of wealth at period $t+1$. From economic theory, we

\footnotetext{
${ }^{7}$ For any positive random variable, say $v$, it can be seen that $\mathrm{E}_{t} \ln v \approx \ln \mathrm{E}_{t} v-\mathrm{V}_{t} v /\left[2\left(\mathrm{E}_{t} v\right)^{2}\right]$.
} 
expect that $\eta>0$, which means that a greater than expected interest rate increases current labor supply. Similarly, individuals or time periods with high risk (reflected by the variance terms) are characterized by a more decreasing labor supply profile than individuals/periods with low risk. ${ }^{8}$

In order to obtain an empirically tractable expression for labor supply dynamics, it is necessary to find an observable analogue for the last terms in (23.25). Hence, it is necessary to understand how the marginal utility of wealth evolves over the life cycle. Two strategies have been relied on for this purpose. Pistaferri (2003) translates the uncertainty and risk on marginal utility of wealth $\lambda_{i, t+1}$ into uncertainty and risk on wages. His strategy relies on two assumptions; one about the expectation error (assumed to follow an MA(1) process), and one linking the marginal utility of wealth to wages, as in (23.14). Lich-Tyler (2002) relies on definition of the marginal utility of wealth to obtain an estimable expression for $\ln \lambda_{i, t+1}-\mathrm{E}_{t} \ln \lambda_{i, t+1}$.

We follow Lich-Tyler's strategy to derive a simplified version of the model. In our time separable framework, let us define the period $t$ indirect utility function: ${ }^{9}$

$$
V\left(r_{t}, w_{i t}, A_{i t}\right)=\max _{C, N}\left\{U(C, \bar{N}-N):\left(1+r_{t}\right) A_{i, t-1}+w_{i t} N=C+A_{i t}\right\} .
$$

Then

$$
\lambda_{i t}=\frac{\partial V}{\partial A}\left(r_{t}, w_{i t}, A_{i t}\right)
$$

which can be used to obtain an expression for $\ln \lambda_{i, t+1}-\mathrm{E}_{t} \ln \lambda_{i, t+1}$. Using a firstorder Taylor approximation to

$$
\lambda_{i, t+1}=\frac{\partial V}{\partial A}\left(r_{t+1}, w_{i, t+1}, A_{i, t+1}\right) .
$$

in the neighborhood of $\mathrm{E}_{t}\left(r_{t+1}, w_{i, t+1}, A_{i, t+1}\right)$, omitting the arguments in the various functions, yields

$$
\begin{aligned}
\lambda_{i, t+1} \simeq & \frac{\partial V}{\partial A}+\left(r_{t+1}-\mathrm{E}_{t} r_{t+1}\right) \frac{\partial^{2} V}{\partial A \partial r}+\left(w_{i, t+1}-\mathrm{E}_{t} w_{i, t+1}\right) \frac{\partial^{2} V}{\partial A \partial w} \\
& +\left(A_{i, t+1}-\mathrm{E}_{t} A_{i, t+1}\right) \frac{\partial^{2} V}{\partial A^{2}} .
\end{aligned}
$$

Hence

$$
\begin{aligned}
\frac{\operatorname{Var}_{t}\left(\lambda_{i, t+1}\right)}{2 \mathrm{E}_{t}\left(\lambda_{i, t+1}\right)^{2}} \simeq & \theta_{A r} \operatorname{Var}_{t}\left(r_{t+1}\right)+\theta_{A w} \operatorname{Var}_{t}\left(w_{i, t+1}\right) \\
& +\theta_{A A} \operatorname{Var}_{t}\left(A_{i, t+1}\right)+\text { covariance terms }
\end{aligned}
$$

\footnotetext{
${ }^{8}$ On that account, it would be interesting to extend the model to allow for individual specific interest rates, and use information on household exposure to financial market risks for evaluating their labor supply behavior.

${ }^{9}$ Strictly speaking, $A_{i, t-1}$ should appear as an argument in function $V$. But examination of (23.28) shows that the corresponding terms are equal to zero, hence the simplification.
} 
with

$$
\theta_{A j} \equiv \frac{1}{2}\left(\frac{\partial^{2} V / \partial A \partial j}{\partial V / \partial A}\right)^{2} \geq 0, \quad j=r, w, A .
$$

Equation (23.28) can also be used to calculate

$$
\begin{aligned}
\operatorname{Cov}_{t}\left(r_{t+1}, \lambda_{i, t+1}\right)= & \frac{\partial^{2} V}{\partial A \partial r} \mathrm{~V}_{t}\left(r_{t+1}\right)+\frac{\partial^{2} V}{\partial A \partial w} \operatorname{Cov}_{t}\left(r_{t+1}, w_{i, t+1}\right) \\
& +\frac{\partial^{2} V}{\partial A^{2}} \operatorname{Cov}_{t}\left(r_{t+1}, A_{i, t+1}\right)
\end{aligned}
$$

For simplicity, we assume that $\operatorname{Cov}_{t}\left(r_{t+1}, \lambda_{i, t+1}\right)$ is constant in the sequel.

Using a first-order Taylor approximation to $\ln \lambda$ in the neighborhood of the realization $\left(r, w_{i}, A_{i}\right)_{t+1}$ gives

$$
\begin{aligned}
\mathrm{E}_{t} \ln \lambda_{i, t+1}= & \mathrm{E}_{t} \ln \frac{\partial V}{\partial A}\left(r_{t+1}, w_{i, t+1}, A_{i, t+1}\right) \\
\simeq & \ln \frac{\partial V}{\partial A}+\left(\mathrm{E}_{t} r_{t+1}-r_{t+1}\right) \frac{\partial^{2} V / \partial A \partial r}{\partial V / \partial A} \\
& +\left(\mathrm{E}_{t} w_{i, t+1}-w_{i, t+1}\right) \frac{\partial^{2} V / \partial A \partial w}{\partial V / \partial A}+\left(\mathrm{E}_{t} A_{i, t+1}-A_{i, t+1}\right) \frac{\partial^{2} V / \partial A^{2}}{\partial V / \partial A}
\end{aligned}
$$

Thus,

$$
\begin{aligned}
\ln \lambda_{i, t+1}-\mathrm{E}_{t} \ln \lambda_{i, t+1} \simeq & -\eta_{A r}\left(r_{t+1}-\mathrm{E}_{t} r_{t+1}\right)-\eta_{A w}\left(w_{i, t+1}-\mathrm{E}_{t} w_{i, t+1}\right) \\
& -\eta_{A A}\left(A_{i, t+1}-\mathrm{E}_{t} A_{i, t+1}\right) .
\end{aligned}
$$

where $\eta_{A A}$ denotes the measure of absolute risk aversion in wealth (in terms of the indirect utility function), and

$$
\eta_{A j} \equiv-\frac{\partial^{2} V / \partial A \partial j}{\partial V / \partial A}, \quad j=r, w, A,
$$

denote the change in marginal utility of wealth due to unanticipated changes in the explanatory variables. Notice that $\ln \lambda_{i, t+1}-\mathrm{E}_{t} \ln \lambda_{i, t+1}$ is uncorrelated with $r_{t+1}$, $w_{i, t+1}$ and $A_{i, t+1}$ under the assumption of rational expectations, see Hansen and Singleton (1982). In this case, former models that have neglected risk, and summed up $\ln \lambda_{i, t+1}-\mathrm{E}_{t} \ln \lambda_{i, t+1}$ with the residual term, mainly incur a loss in information and do not lead to an estimation bias.

Replacing (23.29) and (23.30) into (23.25) and adding a residual term $u_{i t}$ yields

$$
\begin{aligned}
\Delta \ln N_{i t}= & \theta_{0}+\eta\left(\rho-r_{t+1}\right)+\delta \Delta \ln w_{i t} \\
& +\eta_{r}\left(r_{t+1}-\mathrm{E}_{t} r_{t+1}\right)+\theta_{r} \operatorname{Var}_{t}\left(r_{t+1}\right) \\
& +\eta_{w}\left(w_{i, t+1}-\mathrm{E}_{t} w_{i, t+1}\right)+\theta_{w} \operatorname{Var}_{t}\left(w_{i, t+1}\right) \\
& +\eta_{A}\left(A_{i, t+1}-\mathrm{E}_{t} A_{i, t+1}\right)+\theta_{A} \operatorname{Var}_{t}\left(A_{i, t+1}\right)+u_{i t} .
\end{aligned}
$$


The parameter $\theta_{0}$ comprises the covariance terms between the different types of risk. The parameters $\eta_{r} \equiv \eta\left(1-\eta_{A r}\right), \eta_{j} \equiv-\eta \eta_{A j}$, and $\theta_{j} \equiv-\eta \theta_{A j}$ for $j=w, A$, reflect risk aversion with respect to variable $j$. It can directly be seen that risk has a negative impact on $\Delta \ln N_{i t}$. The impacts of unanticipated changes in $w, A$ are asymmetric. In the case where the marginal utility of wealth is decreasing in $w_{i t}, \eta_{A w}>0$, and as $\eta>0$, we have $\eta_{w}<0$. Positive innovations in wages $\left(i . e . w_{i, t+1}>\mathrm{E}_{t} \widetilde{w}_{i, t+1}\right.$ ) lead the individual to work less at $t+1$, whereas negative innovations have the opposite effect. In summary, unanticipated wage changes have the opposite impact to anticipated wage changes.

\subsubsection{Empirical Results}

With this framework it now becomes possible to investigate empirically the impacts of anticipated and unanticipated wage change on labor supply, and how individuals react to an increase in the variability of the lifetime wage profile. For instance, they could adopt a precautionary labor supply behavior in order to try to compensate the risk of a wage profile.

Pistaferri (2003) uses panel data from the Bank of Italy (Survey of Household Income and Wealth), which comprises subjective information for each individual on her anticipated wage profile and price inflation (implying cross-sectional variability in the real interest rates). The difference between observed and anticipated wage gives the unanticipated wage profile. Pistaferri's empirical specification is a special case of (23.31):

$$
\Delta \ln N_{i t} \approx \eta\left(\rho-\mathrm{E}_{t} r_{t+1}\right)+\delta \Delta \ln w_{i t}+\beta \zeta_{i t}+\gamma \operatorname{Var}_{t-1}\left(\zeta_{i t}\right)+u_{i t}
$$

where

$$
\zeta_{i t} \equiv \ln w_{i t}-\mathrm{E}_{t-1} \ln w_{i t} .
$$

Notice that in the neighborhood of zero, $\operatorname{Var}_{t-1}\left(\zeta_{i t}\right) \approx \operatorname{Var}_{t-1}\left(w_{i t}\right) /\left(\mathrm{E}_{t-1} w_{i t}\right)^{2}$.

Lich-Tyler (2002) sums up the unanticipated changes into a residual term $v_{i t}$. Using the wealth identity (23.2), it can be seen that the wealth risk $\operatorname{Var}_{t-1}\left(A_{i t}\right)$ is driven by risk in the interest rate and risk in the future wage path. Assuming "that the wealth risk associated with a permanent wage change depends on the remaining work years of the individual and the amount of wage volatility" (Lich-Tyler, p.18), we write $\operatorname{Var}_{t-1}\left(A_{i t}\right)=A_{i, t-1}^{2} \operatorname{Var}_{t-1}\left(r_{t}\right)+\gamma_{w t} \operatorname{Var}_{t-1}\left(w_{i t}\right)(65-t)$. Putting things together, (23.31) boils down to

$$
\begin{aligned}
\Delta \ln N_{i t}= & \theta_{0}+\eta\left(\rho-r_{t}\right)+\delta \Delta \ln w_{i t}+\gamma \operatorname{Var}_{t-1}\left(\zeta_{i t}\right) \\
& +\alpha_{r} \operatorname{Var}_{t-1}\left(r_{t}\right)+\alpha_{r A} A_{i, t-1}^{2} \operatorname{Var}_{t-1}\left(r_{t}\right)+\alpha_{w t} \operatorname{Var}_{t-1}\left(w_{i t}\right)(65-t)+v_{i t} .
\end{aligned}
$$

Lich-Tyler relies on the PSID data for parameter estimation. In a first stage, the variance terms are estimated from the data, using various regressions. 
Table 23.1 Labor supply estimates accounting for uncertainty and risk

\begin{tabular}{llllllll}
\hline & $\widehat{\eta}$ & $\widehat{\delta}$ & $\widehat{\beta}$ & $\widehat{\gamma}$ & $\widehat{\alpha}_{r}$ & $\widehat{\alpha}_{r A}$ & $\widehat{\alpha}_{w t}$ \\
\hline Pistaferri (i) & 0.59 & 0.70 & -0.20 & -0.11 & - & - & - \\
& $(0.29)$ & $(0.09)$ & $(0.09)$ & $(0.03)$ & & & \\
Pistaferri (ii) & 0.22 & 0.26 & 0.05 & -0.05 & - & - & - \\
& $(0.18)$ & $(0.05)$ & $(0.06)$ & $(0.01)$ & & & \\
Lich-Tyler & 0.01 & 0.29 & - & -0.13 & -12.9 & -0.05 & -0.012 \\
& $(0.04)$ & $(0.09)$ & & $(0.06)$ & $(4.6)$ & $(0.02)$ & $(0.005)$ \\
\hline
\end{tabular}

Some parameter estimates from both contributions are summarized in Table 23.1, estimated standard errors are given in parentheses.

The first line of Table 23.1, Pistaferri (i) shows the result of Pistaferri's basis estimates, whereas the second line, Pistaferri (ii), reports estimates of a model controlling for unemployment constraints. Further model estimations and robustness checks provide support for the first set of results. Pistaferri's estimate of the intertemporal elasticity of substitution is 0.70 , which is somewhat higher than those usually reported. The last line of Table 23.1 gives the estimates obtained by Lich-Tyler. In this case, the elasticity of substitution of 0.29 is in line with those usually obtained from simpler models with the PSID data set. Pistaferri's estimate of the impact of wage innovation is significantly negative in his first model only. It implies that an unexpected $10 \%$ permanent upward shift in the wage profile decreases labor supply in all future periods by about $2.5 \%$.

In all cases, the different types of risk have negative impact on the growth of labor supply. This finding is consistent with precautionary labor supply behavior. The estimates of $\gamma$ are quite similar in the Pistaferri and Lich-Tyler studies. Whereas Pistaferri finds his estimate of wage risk to have a very limited impact on working behavior, Lich-Tyler's conclusions are quite different. His simulations show that wage risk can explain wide differences in working hour profiles (see his Fig. 23.2, p.35).

\subsection{Voluntary and Involuntary Non-participation}

Depending on the economic context, individuals are not always willing to work, or able to find a job, or able to work their desired amount of time. Taking this distinction into account is important for avoiding estimation biases. For instance, if after an increase in wages, a person loses her job, this does not mean that her labor supply decreases in wages. 


\subsubsection{Accounting for the Participation Decision}

The prototype here is the paper by Heckman and MaCurdy (1980) which also presents the first estimation of a Tobit model on panel data. ${ }^{10}$ The specification does not differ much from that of MaCurdy (1981) but now the individual considered is a married woman. Accounting for the participation decision is important because selecting only working individuals leads to a selection bias.

Separability between the leisures of husband and wife is assumed, and the specification chosen for the utility function is

$$
U_{i t}\left(C_{i t}, L_{i t}\right)=\gamma_{C i t} C_{i t}^{\beta}+\gamma_{L i t} L_{i t}^{\alpha_{L}},
$$

with $0<\alpha_{L}<1,0<\beta<1$. Maximization of (23.1) subject to (23.2), taking the possible nonparticipation into account, yields

$$
\ln L_{i t}= \begin{cases}\frac{1}{\alpha_{L}-1}\left(\ln \lambda_{i t}-\ln \alpha_{L}+\ln w_{i t}-\ln \gamma_{L i t}\right) & \text { if } \quad L_{i t} \leq \bar{L}, \\ \ln \bar{L} & \text { otherwise. }\end{cases}
$$

The stochastic assumptions adopted are

$$
\begin{gathered}
\ln \gamma_{L i t}=Z_{i t} \phi+\eta_{1 i}+u_{1 i t}, \\
\ln w_{i t}=X_{i t} \psi+\eta_{2 i}+u_{2 i t} \\
\mathrm{E} u_{j i t}=0, \quad E u_{j i t} u_{k i s}=\delta_{t s} \sigma_{j k}, \quad j, k=1,2, \quad i=1, \ldots, n, \quad s, t=1, \ldots, T .
\end{gathered}
$$

where $\eta_{1 i}$ and $\eta_{2 i}$ are individual fixed effects capturing unobserved heterogeneity in the specifications of $\ln \gamma_{L i t}$ and $\ln w_{i t}$, and $\delta_{t s}$ is the Kronecker symbol. The error terms $u_{1 i t}$ and $u_{2 i t}$ are assumed independent of all other variables in the RHS of (23.34) and (23.35). The unobserved heterogeneity of the preference parameter $\gamma_{L i t}$, which reflects individuals' implicit valuation of leisure, may well be correlated with the unobserved heterogeneity $\eta_{2 i}$ driving the wage of individual $i$. In this case, wages are endogenous in (23.33). Substituting (23.34) and (23.35) into the labor supply function helps to circumvent this problem.

Heckman and MaCurdy consider the reduced form:

$$
\ln L_{i t}=\left\{\begin{array}{l}
f_{i}+\frac{\rho-r}{\alpha_{L}-1} t-Z_{i t} \frac{\phi}{\alpha_{L}-1}+X_{i t} \frac{\psi}{\alpha_{L}-1}+v_{i t} \text { if } \quad L_{i t} \leq \bar{L}, \\
\ln \bar{L} \text { otherwise. }
\end{array}\right.
$$

where

$$
f_{i}=\frac{1}{\alpha_{L}-1}\left(\ln \lambda_{i 0}-\ln \alpha_{L}-\eta_{1 i}+\eta_{2 i}\right),
$$

and

${ }^{10}$ See also Heckman and MaCurdy (1982) 


$$
v_{i t}=\frac{1}{\alpha_{L}-1}\left(-u_{1 i t}+u_{2 i t}\right) .
$$

Equations (23.35) and (23.36) are simultaneously estimated by ML, assuming normality for $u_{1 i t}$ and $u_{2 i t} .{ }^{11}$ Identification of all parameters requires exclusion restrictions between $X$ and $Z$. The fixed effects are $f_{i}$ in the hours equation and $\eta_{2 i}$ in the wage equation. The estimation can only be performed for women who worked at least once in the observed periods. Correction for the corresponding selection bias is found to have only a minor impact. Since asymptotic arguments are not justified in the time dimension (only eight waves), estimates of the fixed effects are not consistent and this leads in principle to the inconsistency of all the coefficients. ${ }^{12}$ However, (i) Heckman (1981) performed Monte-Carlo simulations for fixed effects Probit with eight waves and found that the fixed effects Probit performed well when the explanatory variables were all strictly exogenous, (ii) Tobit should perform even better because it is a combination of Probit and linear regression. The fixed effects (incidental parameters) are estimated simultaneously with the parameters of interest through alternated iteration on both subsets of parameters. ${ }^{13}$ Yet their economic interpretation is difficult because the influence of $f$ is mixed with that of the time invariant variables in $Z_{t}$ and the same holds for $\eta_{2}$ and the time invariant variables in $X_{t}$. Regressions of the fixed effects on those time invariant variables completes the picture and allows one to reach conclusions like the following: current-period household income (exclusive of the wife's earnings) has no significant impact on labor supply, in contrast to an 8 year average income (proxy for the permanent income).

Another study taking the participation decision into account is Jakubson (1988). The specification is the same as above but separate identification of $\psi$ and $\phi$ is left aside and Jakubson specifies $X_{t} \equiv Z_{t}$. The model is thus considerably simplified and takes the Tobit form

$$
\ln L_{i t}= \begin{cases}f_{i}+\frac{\rho-r}{\alpha-1} t+X_{i t} \frac{\psi-\phi}{\alpha-1}+v_{i t} & \text { if } \quad L_{i t} \leq \bar{L} \\ \ln \bar{L} & \text { otherwise }\end{cases}
$$

Jakubson presents three approaches to the estimation of (23.37): simple pooling, treatment of $f_{i}$ as a random effect taking into account the correlation with $X$ (using Chamberlain's, 1984 approach) and, as before, treatment of $f_{i}$ as a fixed effect. For the fixed effects, the considerations above still hold, while convergence for the random effects specification is ensured even for short panels as long as their stochastic specification is correct.

The main conclusions are: (i) the panel estimates (fixed or random effects) of the influence of children on labor supply are only about $60 \%$ of the cross section

\footnotetext{
11 We do not mean to suggest that there are no alternatives to ML with joint normality in this context, and the interested reader is referred to Wooldridge (1995) and Dustmann and Rochina-Barrachina (2000) for some of these.

12 That is, for $N \rightarrow \infty$.

${ }^{13}$ A computationally more efficient alternative is discussed by Greene (2004).
} 
estimates, due to the neglect of individual effects in the latter; (ii) as concerns the life cycle hypothesis, like in the Heckman and MaCurdy study, current income does not have a significant influence in the fixed effects estimation, yet this does not hold true for random effects.

Disregarding the inconsistency problem associated with fixed effects here, and considering that sampling may be endogenous (one of the selection criteria being "stable marriage," see Lundberg, 1988) the fixed effects approach might seem preferable on a priori grounds. However, as we shall see in the following section, the entire specification is questionable.

Accounting for taxes is feasible in the framework discussed here, as documented by Laisney, Lechner, VanSoest and Wagenhals (1993). This study keeps the assumptions of explicit additivity of the intertemporal utility function and of intertemporal separability of the budget constraint. The specification postulates parallel within-period preferences, i.e.

$$
U_{i t}\left(C_{i t}, L_{i t}\right)=G_{i t}\left[C_{i t}+V_{i t}\left(L_{i t}\right)\right]
$$

where $G$ is an increasing function. This specification yields a useful benchmark, because the corresponding labor supply equation is independent of the marginal utility of wealth, $\lambda_{i 0}$ (and thus coincides with the Marshallian and the Hicksian labor supply equations). This clearly solves several of the econometric problems discussed above. Choosing a Box-Cox specification $V_{i t}\left(L_{i t}\right)=\gamma_{i t}\left(L_{i t}^{\alpha_{L}}-1\right) / \alpha_{L}$ and keeping specifications (23.34) and (23.35) for the taste shifter $\gamma_{i t}$ and the gross wage $w_{\text {it }}$ yields the labor supply equation

$$
\ln L_{i t}=\frac{1}{\alpha_{L}-1}\left(\ln w_{i t}+\ln \left[1-\tau_{t}\left(w_{i t} N_{i t}\right)\right]-\ln \gamma_{i t}\right)+v_{i t},
$$

where $\tau_{t}$ denotes the marginal tax rate, assumed here to vary only with earnings. This equation is very similar to (23.33), the specification of Heckman and MaCurdy (1980) apart from the fact that it does not include $\lambda_{i t}$ and $\rho_{i}$. However, as will be discussed in the next section, the Heckman-MaCurdy specification requires the restriction that $G_{i t}$ is the identity, so that, although the two labor supply equations are nested, the overall specifications are not. In the same spirit, it can be seen that the labor supply (23.61) and (23.33) of the Browning, Deaton and Irish (1985) and Heckman and MaCurdy (1980) specifications can be nested in the more general model

$$
\frac{\left(L_{i t}\right)^{\kappa}-1}{\kappa}=-\alpha_{i t}-\delta \ln w^{*}\left(N_{i t}\right)-\theta_{1} \sqrt{\frac{1}{w^{*}\left(N_{i t}\right)}}-\delta \ln \lambda_{i t}+v_{i t},
$$

where $w^{*}\left(N_{i t}\right)$ denotes the real net (marginal) wage rate associated with $N_{i t}$. The Browning et al. specification corresponds to the linear form $\kappa=1$, whereas the Heckman-MaCurdy specification corresponds to the logarithmic specification obtained for the limiting case $\kappa=0$, with $\theta_{1}=0$. 
The model is estimated, taking the participation decision into account, using an unbalanced panel of married women drawn from the German Socio Economic Panel 1985-1989, using Mundlak's (1978) approach to modelling random effects for $\lambda$ and Chamberlain's (1984) minimum distance estimator, whereby the first stage of the estimation procedure consists of (pseudo-) maximum likelihood simultaneous estimation of (23.34), (23.35) and (23.40). Following MaCurdy et al. (1990), the marginal tax rate is approximated by a smooth increasing function. A further distinctive feature of this study is that desired hours of work are used as the dependent variable, instead of effective hours of work. This weakens to some extent the critique of Tobit-type models of labor supply made by Mroz (1987).

\subsubsection{Unemployment}

Certainly one of the most questionable assumptions made so far is the assumption that unemployment is voluntary. Ham (1986) produces empirical evidence against this hypothesis in the context of life cycle models (see also Ashenfelter and Ham, 1979). Ham uses the following modification of MaCurdy's model. If an additional restriction consisting of a ceiling to the number of hours worked exists, and if $T_{u}$ is the set of indices of the periods where this restriction holds for individual $i$, we have

$$
\begin{array}{ll}
\ln N_{i t}<F_{i}+b t-\delta R_{t}+\delta \ln w_{i t}+u_{i t} & \text { for } t \in T_{u}, \\
\ln N_{i t}=F_{i}+b t-\delta R_{t}+\delta \ln w_{i t}+u_{i t} & \text { for } t \notin T_{u},
\end{array}
$$

where $F_{i}$ corresponds to a higher value of $\lambda$ than when $T_{u}=\varnothing$ : the profile of expected wages at each period is lower than in the absence of unemployment periods. Therefore, (23.13) will yield large residuals for $t \in T_{u}$ if unemployment is not the outcome of a free choice. The idea is then to estimate either

$$
\ln N_{i t}=F_{i}+b t-\delta R_{t}+\delta \ln w_{i t}+\theta_{1} U_{i t}+u_{i t}
$$

or

$$
\ln N_{i t}=F_{i}+b t-\delta R_{t}+\delta \ln w_{i t}+\theta_{2} H_{i t}^{u}+u_{i t},
$$

where $U_{i t}=1$ if $t \in T_{u}$ and 0 otherwise, and $H_{i t}^{u}$ denotes yearly hours of unemployment. If the free choice assumption is correct, then $\theta_{1}$ (or $\theta_{2}$ ) will not significantly differ from zero. Otherwise one would expect negative values.

The free choice assumption is clearly rejected for both specifications (23.43) and (23.44), as well as for other specifications allowing for uncertainty, nonlinearity (with the additional term $\left.\left(\ln w_{i t}\right)^{2}\right)$, nonseparability, see (23.61), as well as for various assumptions on the covariance structure of the residuals. The results of these tests suggest modelling these restrictions explicitly. Lilja (1986) makes several proposals in this direction.

However, MaCurdy et al. (1990) criticizes Ham's argument and shows that $\theta_{1}$ (or $\theta_{2}$ ) significant in (23.43) or (23.44) is compatible with voluntary unemployment 
caused by a lower wage offer $w_{i t}$ for $t \in T_{u}$ : "The reasoning underlying the testing of exclusion restrictions in labour supply functions relies on the argument that wages fully capture the influences of demand-side factors in a supply decision. This reasoning is sound but the variable identified as relevant by intertemporal substitution theory is the offer wage; and the offer wage deviates from the observed market wage if unemployment occurs at all" (MaCurdy 1990, p. 228; see also Card, 1987, who interprets Ham's findings in favor of demand-side conditions as the main determinant of observed hours).

\subsection{Alternative Parameterization and Implications}

Browning (1986) and Blundell, Fry and Meghir (1990) point out that the specification of $\lambda$-constant systems, where $\lambda$, or $\ln \lambda$, appear additively and can be treated as an individual-specific effect turns out to be extremely restrictive in the models of MaCurdy (1981) and Browning et al. (1985). In this case, the labor supply functions share the form

$$
g_{i}\left(N_{i t}\right)=f_{i}\left(w_{i t} ; \theta\right)+\delta \ln \lambda_{i t}
$$

where $g_{i}$ and $f_{i}$ are some functions, and $\theta$ and $\delta$ are parameters. After replacing $\ln \lambda_{i t}$ by (23.8), first differentiation for individual $i$ allows us to get rid of individual heterogeneity. The devastating consequence is that such intertemporal preferences are completely identified (up to a monotonic transformation) on a single cross section, given that some variation in the wages or prices can be observed. Thus, this type of specification hardly qualifies for exploiting panel data.

An alternative strategy consists in estimating the within-period preferences by eliminating $\lambda$, either directly between two goods or indirectly via the period budget equation, and then estimating the time preference rate $\rho$ separately. The advantage is that no restriction on within-period preferences is required. Panel data are not absolutely necessary for this strategy: a time series of independent cross sections proves to be sufficient and even has some advantages in providing valid instrumental variables more easily, see Blundell, Fry and Meghir (1990). Blundell, Browning and Meghir (1994) give a good example of the application of this strategy to demands for goods. Four important panel studies on labor supply use this alternative strategy.

MaCurdy (1983) proposes to directly estimate the marginal rate of substitution functions. The first-order conditions (23.3) and (23.4) give

$$
\frac{\partial U_{i t} / \partial N_{i t}}{\partial U_{i t} / \partial C_{i t}}=-w_{i t} .
$$

The advantage over estimating Marshallian demands is that this allows estimation of preferences that do not imply a closed-form expression for the demand functions. The estimation of (23.46) does not require a panel. A cross section with enough price variation, or indeed a time series of cross sections, can be sufficient. 
In spite of this, MaCurdy chooses the restrictive form

$$
U_{i t}=G_{i t}\left(U_{i t}^{*}\right)=\xi_{i t} \frac{\left(U_{i t}^{*}+v\right)^{\sigma}-1}{\sigma},
$$

with

$$
U_{i t}^{*}=\gamma_{i t} \frac{\left(C_{i t}+\theta_{C}\right)^{\alpha_{C}}}{\alpha_{C}}-\frac{\left(N_{i t}+\theta_{N}\right)^{\alpha_{N}}}{\alpha_{N}},
$$

and

$$
\begin{aligned}
\xi_{i t} & =\exp \left[X_{i t} \phi+\alpha_{i t}\right], \\
\gamma_{i t} & =\exp \left[X_{i t} \psi+\varepsilon_{i t}\right] .
\end{aligned}
$$

The parameters $\phi, \psi, \sigma, v, \theta_{C}, \theta_{N}, \alpha_{C}$, and $\alpha_{N}$ are constant across individuals and over time. This utility function is still additive, yet no longer explicitly additive, and this form of $U_{t}^{*}$ allows for several well-known special cases such as CES, addilog and Stone-Geary. The Frisch labor supply function corresponding to (23.47) is usually different from (23.45). There is no identification problem here since (23.49) and (23.50) are estimated in two different dimensions: (23.50) is estimated in the "individual" dimension and (23.49) in the "time" dimension. Equations (23.46) and (23.48) yield

$$
\ln w_{i t}=-X_{i t} \psi+\left(\alpha_{N}-1\right) \ln \left(N_{i t}+\theta_{N}\right)-\left(\alpha_{C}-1\right) \ln \left(C_{i t}+\theta_{C}\right)-\varepsilon_{i t},
$$

which provides consistent estimates (on a single cross section if desired) for $\psi, \alpha_{N}$, $\alpha_{C}, \theta_{N}$ and $\theta_{C}$. Using those one can obtain $\gamma_{i t}$ by substitution of $X_{i t} \psi+\varepsilon_{i t}$ from (23.51) into (23.50). Estimates for the parameters $\sigma$ and $\phi$ can be obtained as follows. Substitution of (23.3) into (23.6) gives

$$
\ln \left(\frac{\partial U_{i t}}{\partial C_{i t}}\right)=r_{t+1}-\rho_{i}+\ln \left(\frac{\partial U_{i, t+1}}{\partial C_{i, t+1}}\right)+e_{i, t+1} .
$$

The above specification leads to

$$
\begin{aligned}
\ln \frac{\partial U_{i t}^{*}}{\partial C_{i t}}-\ln \frac{\partial U_{i, t+1}^{*}}{\partial C_{i, t+1}}= & r_{t+1}-\rho_{i}-\left(X_{i, t+1}-X_{i t}\right) \phi \\
& +(1-\sigma)\left[\ln \left(U_{i t+1}^{*}+v\right)-\ln \left(U_{i t}^{*}+v\right)\right]+e_{i, t+1} .
\end{aligned}
$$

Since estimates for $U_{i t}^{*}$ and $\partial U_{i t}^{*} / \partial C_{i t}$ are available from the parameter estimation of (23.51), specification (23.53) can be seen as a regression from which the still unknown parameters $\phi$ and $\sigma$ of the monotonic transformation $G_{i t}$ can now be identified. Either time series or panel data contain all the information needed to estimate (23.53). Instrumental variables are necessary to take account of the endogeneity of $U_{i t}^{*}$ and $U_{i, t+1}^{*}$, and Pagan's (1984) method of correcting the variance of 
the estimators would be advisable here, because estimated parameters are used in the construction of regressors as well as regressands in (23.53). Taking account of measurement errors in hours, wages or consumption would be difficult because such errors would contaminate $\varepsilon_{i t}$, see (23.51), and would therefore produce nonlinear errors in the variables in (23.53).

The study of Blundell et al. (1993) of intertemporal labor supply of married women starts from the following Marshallian supply specification for within-period desired hours of work

$$
N_{i t}=\alpha\left(w_{i t}, Z_{i t}\right)-\beta\left(w_{i t}, Z_{i t}\right)\left[S_{i t}+a\left(w_{i t}, Z_{i t}\right)\right]+u_{i t},
$$

where $w_{i t}$ is the real marginal after tax wage rate, $S_{i t}$ is a measure for unearned income and $Z_{i t}$ is a vector of characteristics. This supply function can be derived by Roy's identity from the indirect utility function

$$
V\left(w_{i t}, S_{i t}, Z_{i t}\right)=\frac{1}{1+\rho\left(Z_{i t}\right)}\left[\left(\frac{S_{i t}+a\left(w_{i t}, Z_{i t}\right)}{b\left(w_{i t}, Z_{i t}\right)}\right)^{1+\rho\left(Z_{i t}\right)}-1\right],
$$

with $\alpha\left(w_{i t}, Z_{i t}\right)=\partial a / \partial w_{i t}$ and $\beta\left(w_{i t}, Z_{i t}\right)=\left(\partial b / \partial w_{i t}\right) / b$. The parameters of $\rho\left(Z_{i t}\right)$ which do not show up in the labor supply function are estimated in a second stage, using GMM and relying on a procedure analogue to (23.53). Although the study discusses several different elasticities, we shall only comment on $\lambda$-constant elasticities of labor supply with respect to the net wage, computed at the means of various subsamples of employed women. These range between 0.57 for childless women with unemployed blue-collar husbands and 1.39 for women whose youngest child is at most two and whose husbands are employed white-collars, a subsample with typically low labor supply.

More on taxes: relaxing the intertemporal separability of the budget constraint. As pointed out by Blomquist (1985), capital taxation will usually break the intertemporal separability of the intertemporal budget constraint. When the constraints (23.2) are replaced by

$$
A_{i t}=\left(1+r_{t}\right) A_{i, t-1}+w_{i t} N_{i t}-C_{i t}-T\left(w_{i t} N_{i t}+r_{t} A_{i, t-1}\right), \quad t=1, \ldots, T,
$$

where the function $T$ denotes the tax scheme. In this case, it is in general not possible to write the Frisch labor supply in function of an additive and constant $\lambda$-term which can be easily differentiated out. Ziliak and Kniesner (1999) consider instead a Marshallian labor supply function of the form

$$
N_{i t}=\alpha w_{i t}+\delta A_{i, t-1}+\phi A_{i t}+Z_{i t} \gamma+\eta_{i}+\xi_{i t},
$$

where $\eta_{i}$ denotes an individual effect. The wealth measure used for $A_{i t}$ is a construct analogue to the familiar virtual income used in static models of labor supply with taxes. Notice that both current assets and assets in the previous period condition this labor supply function, which is thereby different from the pseudo supply function 
$\widetilde{N}_{i t}\left(A_{i t}-\left(1+r_{t}\right) A_{i, t-1}, w_{i t}\right)$ of Sect. 23.2. Parameters reflecting the intertemporal utility function are then recovered in a second stage which is very similar to (23.52-23.53).

In contrast with Blundell et al., Ziliak and Kniesner use (balanced) panel data (PSID for 1978-1987), 532 continuously married, continuously working men aged 22-51 in 1978), in both stages of the estimation procedure. In the first stage, this has the advantage of allowing a better control of unobserved heterogeneity. Ziliak and Kniesner estimate (23.56) in first differences by optimal GMM assuming absence of autocorrelation in the process $\xi_{i t}$, using internal instruments dated $t-2$ and other instruments dated $t-1$ and $t-2$. Estimation in the second stage is conducted on the same panel, with internal instruments dated $t-4$ and other instruments dated $t-3$ and $t-4$. A consistent estimator of the variance of the second stage estimator, taking into account the variability of the estimated quantities, is obtained following Newey (1984). Our impression is that potentially important efficiency gains might be obtained quite easily by (a) moving from a balanced to an unbalanced panel, which would substantially increase the number of observations, and (b) extending the instrument set by taking instruments dated up to the named dates rather than only instruments at the above dates.

Results from Step 1 show that the model conditioning on assets at two subsequent dates outperforms a model conditioning on savings. Two series of estimates are presented for Step 2, depending on whether the subjective discount rate, assumed constant over time, is allowed to vary over individuals or not. The former specification is the preferred one. Even though the $\lambda$-constant specification was not used for parameter estimation, the $\lambda$-constant elasticities of labor supply with respect to the gross wage are easily computed from (23.56). Mean $\lambda$-constant elasticities by wealth quartile vary between 0.14 for the lowest quartile and 0.20 for the highest. Recall that this represents the response to an expected wage change. By contrast the authors reckon that the average elasticity of labor supply with respect to an unexpected wage change will be roughly constant across wealth quartiles, at about 0.16 . Ziliak and Kniesner also compute deadweight loss measures associated to four tax reforms, but reporting on these would take us too far off our track.

Errors in variables are thoroughly treated by Altonji (1986), using instrumental variables methods. Unfortunately, in order to obtain the required linearity, Altonji uses a version of MaCurdy's (1981) restrictive form, i.e. an explicitly additive within-period utility function

$$
U_{i t}=\frac{\gamma_{C i t}}{\alpha_{C}} C_{i t}^{\alpha_{C}}-\frac{\gamma_{N i t}}{\alpha_{N}} N_{i t}^{\alpha_{N}},
$$

where $\gamma_{C i t}$ and $\gamma_{N i t}$ are time-varying taste modifiers. The $\lambda$-constant demands are

$$
\begin{gathered}
\ln N_{i t}=\mathrm{cst}+\delta_{N}\left[\ln w_{i t}+\ln \lambda_{i t}+t \ln (1+\rho)-\ln \gamma_{N i t}\right], \\
\ln C_{i t}=\mathrm{cst}+\delta_{C}\left[\ln \lambda_{i t}+t \ln (1+\rho)-\ln \gamma_{C i t}\right] .
\end{gathered}
$$


Rather than estimating (23.58) in first differences, ${ }^{14}$ Altonji proposes substituting $\ln \lambda_{i t}+t \ln (1+\rho)$ out of (23.58) and (23.59). He then assumes that the observations contain the measurement errors $v_{N i t}^{*}, v_{C i t}^{*}$, and $e_{i t}^{*}$, and consist in $n_{i t}^{*}=\ln N_{i t}+$ $v_{N i t}^{*}, c_{i t}^{*}=\ln C_{i t}+v_{C i t}^{*}$ and $w_{i t}^{*}=\ln w_{i t}+e_{i t}^{*}$. Since $w_{i t}$ is not directly observed but is calculated by dividing period income by $N_{i t}, v_{N i t}^{*}$ is correlated with $e_{i t}^{*}$ but neither of the two will be correlated with $v_{C i t}^{*}$. Thus, we obtain the model:

$$
n_{i t}^{*}=\operatorname{cst}+\delta_{N} w_{i t}^{*}+\frac{\delta_{N}}{\delta_{C}} c_{i t}^{*}+\delta_{N} \ln \frac{\gamma_{C i t}}{\gamma_{N i t}}+v_{N i t}^{*}-\delta_{N} e_{i t}^{*}-\frac{\delta_{N}}{\delta_{C}} v_{C i t}^{*} .
$$

The advantage over first differences is that the substitution using $c_{i t}^{*}$ does not bring lagged wages into the equation. Even more important perhaps, the assumption about expectations that was used above to motivate estimating first differences under uncertainty is now unnecessary. Instruments are used for $w_{i t}^{*}$ and $c_{i t}^{*}$. The results do not differ much from MaCurdy's. See also Imai and Keane (2004) for a different treatment of the problem of errors in variables.

\subsection{Relaxing Separability Assumptions}

We now discuss studies relaxing within-period and between-period additive separability.

\subsubsection{Relaxing Within-Period Additive Separability}

When the within period utility function is additively separable, the Frisch demand functions satisfy the restrictions

$$
\frac{\partial N}{\partial \lambda_{i t}} \frac{\lambda_{i t}}{N}=\frac{\partial N}{\partial w_{i t}} \frac{w_{i t}}{N} \text { and } \quad \frac{\partial C}{\partial w_{i t}}=0,
$$

see (23.12). These restrictions are not simply a consequence of the functional form adopted in (23.12), indeed they characterize within-period additive separability. The importance of relaxing the assumption of separability between leisure and goods is indicated in Browning and Meghir (1991) who reject this assumption, testing it within a very general scheme using 1979-1984 FES data (time series of cross sections): preferences about goods are specified in a flexible way, with conditional cost functions where no behavioral assumption concerning labor supply or participation decision is needed. ${ }^{15}$ Here we shall be concerned only with relaxing the assumption of additive separability between the two "goods" leisure and aggregate consumption.

\footnotetext{
${ }^{14}$ Yet this is done for comparison.

${ }^{15}$ Yet their model is not cast in the life cycle framework and the implications of their study for life cycle models should be elucidated.
} 
Browning et al. (1985) estimate the following specification in first differences:

$$
\begin{gathered}
N_{i t}=\alpha_{1}\left(a_{i t}\right)+\delta \ln w_{i t}+\theta_{1} \sqrt{\frac{1}{w_{i t}}}+\delta \ln \lambda_{i t}, \\
C_{i t}=\alpha_{2}\left(a_{i t}\right)-\theta_{2} \sqrt{w_{i t}}+\beta \ln \lambda_{i t},
\end{gathered}
$$

where $a_{i t}$ is a vector of household characteristics. Symmetry of the demand functions implies that $\theta_{1}=\theta_{2}=\theta$ and within-period additive separability is equivalent to $\theta=0$. Browning et al. (1985) estimate the equations separately, i.e. they do not enforce the identity $\theta_{1}=\theta_{2}$, as would be feasible in this context since there is no adding-up restriction (in contrast with a Marshallian demand system). However, they find $\theta_{1}$ and $\theta_{2}$ to be significantly different from zero and to have opposite signs, which makes the entire specification appear questionable. Note that, although Browning et al. consider aggregate consumption, no problem arises from working with several consumption goods. Yet, durables should be given special attention, as they might be more properly treated as assets.

So far we have focused on the preferences of an individual. In practice, however, economists often work with "household preferences". One of the many reasons for doing this is the difficulty of isolating individual from household consumption in survey data. Another assumption, which is necessary for the validity of the specifications that we have considered so far is the separability of the labor supplies of the different potential earners in a household. If it holds, the earnings of the other household members can be accounted for in $A_{i t}$, because then the influence of hours and wages of other household members boils down to a pure income effect. Otherwise the model is misspecified.

\subsubsection{Relaxing Intertemporal Separability in Preferences}

Although relaxing this assumption is no easy task, it is important because all the studies that test the assumption clearly reject it. If the estimation results are to be used in policy analysis, the specification must produce interpretable parameters and not merely a separability test. In this respect, it seems difficult to simultaneously model the multiple reasons that lead to the rejection of separability. Most empirical studies therefore concentrate on only one of these aspects. The modelling of partial adjustment, rational habit formation and human capital accumulation in an optimization scheme over the life cycle is such a feasible extension.

Yet, before turning to structural models relaxing the intertemporal separability assumption, it is interesting to discuss the results of a VAR approach to modelling the relationship between wages and hours of work using panel data. As a prototype for this kind of approach we will focus on the study by Holtz-Eakin, Newey and Rosen (1988), but also refer the reader to Abowd and Card (1989).

Holtz-Eakin et al. analyze a sample of 898 males from the Panel Study of Income Dynamics (PSID) over 16 years. They estimate linear equations for wages and 
hours, with lags of equal lengths on both wages and hours on the right hand side of each equation, and individual effects. Note that the equation on hours does not nest the simple life-cycle model of MaCurdy (1981) since the contemporaneous wage is excluded and no serial correlation is allowed. By contrast, the form of the wage equation could be justified by human capital considerations. However, attempts at interpreting these reduced form equations are not in line with the VAR approach. The model of Holtz-Eakin et al. does not a priori impose the stationarity of the coefficients over time, not even for the individual effect. The estimation strategy relies on GMM, combined with quasi-differencing along the lines of Chamberlain (1984, p. 1263) in order to eliminate the individual effect while allowing for nonstationarity. Errors in variables are easily dealt with in this linear GMM framework, but again under the restrictive assumption of no serial correlation. Starting with a maximum lag length of three periods (involving four lags of the original variables in the quasidifferenced equations) parameter stability is rejected for none of the two equations, and the analysis proceeds more simply with first differences. The next step concerns testing the lag-length, and the assumption that one lag is sufficient to describe the data is rejected in no equation at the $1 \%$ level, but rejected in the hours equation at the $5 \%$ level.

Furthermore, one cannot reject the assumption that lagged hours could be excluded from the wage equation. The same holds for lagged wages in the hours equation, when using only one lag, but not if two lags are retained (an argument in favor of nesting the noncausality test within the hypothesis about the lag length is that in this way the test statistics turn out to be asymptotically independent, which facilitates pin-pointing the reasons for rejection of the joint hypothesis). Tests for measurement error bias are constructed using internal instruments in the simple first-order autoregressive models, in order to increase the power of the test. The assumption of absence of measurement error cannot be rejected at the $5 \%$ level, but there is evidence that the test may have low power in this instance. Most results are qualitatively, and, what is more surprising, quantitatively replicated on a sample from the National Longitudinal Survey (NLS). The authors conclude (p. 1393): "Our empirical results are consistent with the absence of lagged hours in the wage forecasting equation, and thus with the absence of certain human capital or dynamic incentive effects. Our results also show that lagged hours are important in the hours equation, which is consistent with the alternatives to the simple labour supply model that allow for costly hours adjustment or preferences that are not time separable [our emphasis]. As usual, of course, these results might be due to serial correlation in the error term or functional form misspecification".

\subsubsection{Rational Habit Formation}

Bover (1991) estimates a rational habits model in a certainty framework with a minimum amount of replanning. The salient feature of her approach is that the model specification is constructed in such a way that it allows for an explicit expression of the marginal utility of wealth $\lambda$, as a function of future wages, initial wealth, 
the (constant) interest rate, and preference parameters. The advantage of such an expression is that it allows a direct analysis of wealth effects on intertemporal labor supply (see Card, 1994, for the potential importance of such effects), whereas the approach of MaCurdy (1981) allows such an analysis only in a very indirect and unsatisfactory way. However, this comes at a large cost, as we shall see. In period $t$ the individual maximizes

$$
\sum_{t=1}^{T} \frac{1}{(1+\rho)^{t-1}}\left[\left(1-\beta_{i t}\right) \ln \left(C_{i t}-\gamma_{c}\right)+\beta_{i t} \ln \left(\gamma_{N}+\phi N_{i, t-1}-N_{i t}\right)\right]
$$

subject to (23.2). The parameter $\phi$ now measures the habit persistence. The Stone-Geary specification (23.63) was also used by Ashenfelter and Ham 1979 in order to derive an explicit expression for $\lambda_{i t}$ under perfect foresight. The novel feature here lies in the relaxation of the intertemporal separability assumption through the rational habit formation assumption. (In a previous paper Bover, 1986, considered two alternative models, one with partial adjustment and one with myopic habit formation, which did not take account of all direct and indirect influences of current labor supply on future decisions, as the rational habit formation model does, but she found all these models to be empirically indistinguishable.)

Defining $N_{i t}^{*}=N_{i t}-\phi N_{i, t-1}$ and $w_{i t}^{*}=\sum_{j=0}^{T-t}(1+r)^{-j} \phi^{j} w_{i, t+j}$ allows one to rewrite (23.63) and (23.2) in the usual form of a separable intertemporal utility function with arguments $\left\{N_{i t}^{*}, C_{i t}\right\}_{t=1, \ldots, T}$ and an additively separable intertemporal budget constraint. The corresponding Frisch demands are linear in $\lambda_{i t}$ and the expression of the latter is obtained by substituting these into the budget constraint. The reason for the subscript $t$ in $\lambda_{i t}$ is the replanning that takes place at each period, when the individual forms new predictions about his wage profile. The somewhat arbitrary assumption here is that each individual's future wages lie on a specific linear time trend, and that the individual learns more about the two coefficients of this relationship as more time passes by. This is disturbing, because if the relationship were deterministic, two observations would suffice to pin it down without any error, and if not we have uncertainty about future wages, whereas the derivation of $\lambda_{i t}$ assumed that $w_{i t}^{*}$ is known.

This specification yields a nonlinear model where the dynamics are only present in the error term. The model can be exactly linearized through transformations of the exogenous variables on the one hand, and the parameters on the other. The error specification is of the error components type with the unobserved heterogeneity subsumed in a time-invariant individual effect. Bover estimates the dummy variable model with unrestricted covariance for the residual error term, including also time dummies and using instruments to cope with potential endogeneity and measurement error problems concerning the wage variable. The instruments used have the property that they are strictly exogenous conditional on the individual effect. A $\chi^{2}$ test of the overidentifying restrictions leads to no clear-cut rejection of the specification. The results show that lagged hours have a significant effect on the current decision. 
While Bover substitutes the marginal utility of wealth in the Euler equation with a very special assumption about the wage path, Hotz, Kydland and Sedlacek (1988) (HKS) consider the stochastic Euler equations, characterizing the first-order conditions of the dynamic optimization problem. This strategy allows to consider more general specifications for the utility functions. In period $t$ the individual maximizes

$$
\mathrm{E}_{t} \sum_{t=1}^{T} \frac{1}{(1+\rho)^{t-1}} U_{i t}\left(C_{i t}, L_{i t}+\alpha a_{i t}\right) \text {, }
$$

with

$$
a_{i t}=(1-\eta) a_{i, t-1}+L_{i, t-1},
$$

subject to (23.2). As before $L_{i t}$ denotes leisure. This specification nests intertemporal separability $(\alpha=0)$ and the models of Johnson and Pencavel (1984) and Bover $(1986,1991)$, where only the labor supply of the previous period does play a role in the preferences of the current period $(\eta=1)$.

In order to avoid misspecification, stemming from potential endogeneity of wages, HKS only use the Euler equation for consumption. They specify $U_{i t}$ to be translog and separately estimate the parameters for two age groups. Since parameters $\alpha$ and $\eta$ are identified under the maintained assumption of no contemporaneous additive separability between $L_{i t}+\alpha a_{i t}$ and $C_{i t}$, this allows testing the form of the intertemporal nonseparability in preferences. Moreover, a score test of the wage exogeneity is offered. HKS also explain how to cope with a certain degree of correlation between individuals through macroeconomic shocks or regional variables. Using a sample of 482 men from the PSID, they reach the following conclusions. The estimated parameters $\alpha$ and $(1-\eta)$ are positive and well determined and therefore intertemporal separability is rejected, and not only $L_{i, t-1}$ but also leisure decisions in previous years have a direct influence on current decisions. The (within period) separability between $L_{i t}+\alpha a_{i t}$ and $C_{i t}$ in the translog utility function is also rejected, as is exogeneity of the wages. A slightly disturbing result is the negativity of the estimated rate of time preference.

The theoretical setting (Euler equation) implies orthogonality between the residual at time $t$ and all the information available up to $t-1$. Thus, in GMM estimation, all variables dated $t-1$ or earlier qualify in principle as instruments for the equation dated $t$. This implication of theory can be tested by a $\chi^{2}-$ test of overidentifying restrictions using two sets of instruments, where one is restricted to strictly exogenous instruments. HKS conduct such a test and do not reject the null of orthogonality.

\subsubsection{Human Capital Formation}

Hotz et al. and Bover assume that the wage path is not influenced by the hours decision, thus assuming intertemporal separability in the budget constraint. By contrast, Shaw (1989) and Imai and Keane (2004) relax that assumption, i.e. they allow for nonseparability in the budget constraint (but not in the preferences). For Shaw, $\alpha=0$ in (23.64). The budget restriction is as before given by (23.2). However, Shaw 
defines the real wage $w_{i t}$ as the product $R_{i t} K_{i t}$ of the human capital stock $K_{i t}$ and its rental rate $R_{t}$ and chooses a quadratic approximation $f$ for the relationship between $K_{i, t+1}$ on the one side and $K_{i t}$ and $N_{i t}$ on the other side, which yields the atypical earnings function

$$
\frac{w_{i, t+1}}{R_{i, t+1}}=f\left(N_{i t}, \frac{w_{i t}}{R_{i t}}\right) .
$$

Although Shaw considers a timewise separable direct utility function, this last equation, which makes future wages an increasing function of the current wage, renders the indirect utility function nonseparable. The first-order optimality condition with respect to leisure now reads:

$$
\frac{\partial U_{i t}}{\partial L_{i t}}=\lambda_{i t} w_{i t}\left(1+R_{i t} \frac{\partial f^{-1}}{\partial N_{i t}} \frac{N_{i t}}{w_{i t}}\right), \quad t=1, \ldots, T,
$$

which differs from the timewise separable optimality condition (23.4). When working today increases future wages, this leads individuals to work more as predicted by timewise separable models. ${ }^{16}$ Imai and Keane (2004) provide a further contribution along these lines.

Shaw specifies $U_{i t}$ to be translog (as in HKS). Preference parameters are estimated by GMM using the orthogonality conditions in the stochastic Euler equations. This contrasts with Imai and Keane (2004) who solve the stochastic dynamic programming problem backwards.

Shaw's conclusions are as follows. The rental rate of human capital varies considerably over time and the number of hours worked has a strong influence on future wages. This result offers a possible explanation for the misspecification of the usual static earnings function. Because of the model structure and especially the fact that the nonlinearity is within the budget constraint, the overall implications of the model can only be evaluated by simulation. This reveals that the intertemporal elasticity of labor supply is not constant as is usually assumed in static models, but instead rises over the life cycle. Her model is estimated over a samples of 526 men from the PSID. Due to the high degree of nonlinearity in the Euler equations, Shaw does not handles measurement errors or unobserved heterogeneity. In particular, the presence of unobserved heterogeneity is problematic as it can bias the conclusions about state dependence in dynamic models (see Chamberlain, 1984).

A reason why the models of Shaw and HKS have been estimated with male rather than with female labor supply may be that the estimation method used does not readily extend to discrete data. Altug and Miller (1991) propose a solution to that problem. We shall not go into the details of their paper, but it seems worth mentioning that this is a very sophisticated and innovative study, which also

\footnotetext{
${ }^{16}$ Notice that for the alternative specification allowing the earning function $f$ to depend on the cumulative hours of work (and concave in this variable), there are especially young individuals who have incentives to work more whereas older individuals for which human capital investment become less attractive - given the fact that retirement is nearer than for young individuals - to work less.
} 
considerably improves upon the treatment of aggregate shocks adopted by the two studies just mentioned. The main drawback is that estimation of the model of Altug and Miller is intricate, combining GMM with simulation of participation probabilities and iterative estimation of Euler equations, including nonparametric regressions at each iteration. In short, it required the use of a supercomputer. Another drawback, a theoretical one, is that the model heavily relies on the assumption that actual hours of work differ from expected or contracted hours of work in a stochastic manner. While this may be attractive for some occupations (think of academics), it is much less convincing for most others. To our knowledge, this is the only study of female labor supply allowing for nonseparability both in the preferences and in the budget constraint.

The study of Eckstein and Wolpin (1989), which is based on explicit solution of the dynamic optimization problem facing individuals rather than on the exploitation of first-order conditions, shares this generality but restricts attention to the participation decision and disregards aggregate shocks. Hence it does not exactly fit the framework of this survey. ${ }^{17}$ It has however inspired the work of Imai and Keane (2004), to which we now turn. The main goal of their study is to reconcile the microeconometric evidence on the ies with the higher values adopted by macroeconomists in the calibration of real business cycle models. Their framework assumes both intertemporal and within period additive separability of preferences, but it allows for on-the-job human capital accumulation to affect the wage path, which breaks intertemporal separability in the budget constraint, as in Shaw (1989). It also allows for measurement errors in wages, labor supply, and assets in a maximum likelihood framework with fully parametric distributional assumptions. Missing data on assets are also handled through both distributional assumptions and the intertemporal budget constraint. The functional forms adopted for the subutility functions from consumption and leisure are the same as in MaCurdy (1981), except for the presence of age effects in the former. The intertemporal budget constraint is again (23.2) where $t$ denotes the age of the individual, and the real wage rate $w_{t}$, assimilated with the human capital stock, evolves according to

$$
w_{t+1}=g\left(N_{t}, w_{t}, t\right) \varepsilon_{t+1},
$$

where $\varepsilon_{t+1}$ is a wage shock and $g$ is a deterministic function of hours worked and human capital at age $t$, and age itself.

Imai and Keane argue that neglecting human capital accumulation biases ies estimates towards zero. On the one hand, as the wage increases over the life-cycle, the substitution effect leads to an increase in labor supply. On the other hand, concavity of the value function in human capital lowers the rate of return to human capital investment and reduces the incentive to supply labor. The combination of the two effects leads to a fairly flat hours-wage profile, and attributing this to the substitution effect only leads to an underestimation of the ies.

Indeed, estimating their model on a fairly homogeneous sample of 1000 randomly chosen white males from the 1979 cohort of NLSY observed at ages 20-36

${ }^{17}$ A summary of that study is in the 1996 version of this survey. 
and continuously reporting positive yearly hours of work, Imai and Keane obtain an estimate of the ies of 3.82 with a very small standard error. ${ }^{18}$ They then simulate data from their model over the life-cycle up to age 65 and estimate the ies on various subsets using the OLS and IV methods of MaCurdy and Altonji. The results show that the estimated ies is much lower in these estimates than the true ies in the simulated data, and that estimates are particularly low for individuals in the 20-36 age group, underscoring the fact that the human capital component of the return to labor supply is much greater for the young. Indeed, IV results obtained from the original data yield an ies below 0.3, more than ten times smaller than the ML estimate.

Imai and Keane (2004) estimate the marginal rate of substitution between consumption and labor supply, which corresponds to $w_{i t}\left[1+R_{i t}\left(\partial f^{-1} / \partial N_{i t}\right)\left(N_{i t} / w_{i t}\right)\right]$ in (23.66). Their results range from about $2 w_{i t}$ for 20 years old individuals to $w_{i t}$ for 60 years old. This means that the effective wage is higher than market wages $w_{i t}$ due to high return in human capital, which induces young people to work more (at given wage) than predicted by (23.4).

\subsection{Conclusion}

Taking stock, we can draw the following conclusions. Firstly, in our opinion, there has so far still being too little emphasis on the relaxation of ad hoc functional form assumptions. In a way, this is understandable, because researchers have been busy introducing and manipulating new and sometimes complex econometric methods. Yet it is disturbing to see how popular the additively separable Box-Cox type specification has remained over the 25 past years, even in studies allowing much more flexible approaches. The greater flexibility of the alternative to Frisch demands, consisting in separate estimation of within-period and intertemporal preference parameters, has not yet been used fully in life-cycle labor supply studies. Secondly, given the small sample sizes and the more or less pronounced arbitrariness of the selection, most of the studies we have discussed definitely have a methodological rather than a substantive character.

Before closing this chapter we would still like to point out a series of papers which do not completely fit under its heading but contribute to the understanding of labor supply reactions. Blundell, Duncan and Meghir (1998) use past fiscal reforms in order to estimate labor supply responses. For estimation they rely on a series of cross-sections but their innovative approach can easily be adapted to panel data. A growing body of literature relies on daily information on wages and working time for particular worker groups to investigate the sensitivity of working time to wages: cabdrivers have been considered by Camerer, Babcok, Loewenstein and Thaler (1997) and by Farber (2005), stadium vendors by Oettinger (1999), bicycle messengers by Fehr and Götte (2007). This type of data exhibits two important

\footnotetext{
18 The estimation method is too complex to be described in any detail in a survey. It entails several clever approximations aiming at reducing the number of evaluation points and the dimension of the optimisation space.
} 
advantages over usual panel data: these workers choose daily the number of working hours they want to work, and daily variations of their hourly wage can reasonably be considered as transitory changes. Their results tend to suggest a negative relationship between wages and working hours. Finally, there is a burgeoning literature on the estimation of collective models of household labor supply, i.e. models where the existence of autonomous decision makers within the household is explicitly acknowledged, and the central assumption is that household allocations are Pareto efficient. For instance, Blundell, Chiappori, Magnac and Meghir (2005) estimate a static model on repeated cross-sections, focusing on the participation/nonparticipation decision of the husband while allowing free choice of hours for the wife (including nonparticipation). The longitudinal information contained in panel data allows the study of intertemporal household allocations in the collective framework, as exemplified by Mazzocco (2007).

Acknowledgments This is an update on Chap. 28 of the 1996 edition of this book. Besides incorporating new references, we also modified the focus. The reader is referred to the former version for a summary of quantitative results, as well as for data issues. We would like to thank Richard Blundell, Tom Kniesner, Gauthier Lanot, Michael Lechner, Friedhelm Pfeiffer, Jörn-Steffen Pischke, Jean-Marc Robin and Gerhard Wagenhals for comments.

\section{References}

Abowd, J. and D. Card (1989): "On the Covariance Structure of Earnings and Hours Changes," Econometrica, 57(2), 411-445.

Altonji, J.G. (1986): "Intertemporal Substitution in Labour Supply: Evidence from Micro-Data," Journal of Political Economy, 94 (3.2), S176-S215.

Altug, S. and R.A. Miller (1990): "Household Choices in Equilibrium," Econometrica, 58, 543-570.

Altug, S. and R.A. Miller (1991): "Human Capital Accumulation, Aggregate Shocks and Panel Data Estimation,” Discussion Paper 9128, CentER, Tilburg University.

Ashenfelter, O. and J. Ham (1979): “Education, Unemployment and Earnings," Journal of Political Economy, 87, S99-S116.

Blomquist, S. (1985): "Labour Supply in a Two-Period Model: The Effect of a Nonlinear Progressive Income Tax," Review of Economic Studies, 52, 514-524.

Blundell, R.W. (1987): "Econometric Approaches to the Specification of Life-Cycle Labor Supply and Commodity Demand Behaviour," Econometric Reviews, 6(1), 147-151.

Blundell, R.W. (1988): "Consumer Behaviour: Theory and Empirical Evidence - A Survey," Economic Journal, 98, 16-65.

Blundell, R.W and T. MaCurdy (1999): "Labor Supply: A Review of alternative Approaches," in Handbook of Labor Economics, Volume 3A, O. Ashenfelter and D. Card (eds.), Elsevier Science, Amsterdam.

Blundell, R.W. and C. Meghir (1990): "Panel Data and Life Cycle Models," Chapter 2 in Panel Data and Labour Market Studies, J. Hartog, G. Ridder and J. Theeuwes (eds.), North Holland, Amsterdam.

Blundell, R.W., M. Browning and C. Meghir (1994): "Consumer Demand and the Life-Cycle Allocation of Household Expenditures," Review of Economic Studies, 61, 57-80.

Blundell, R.W, A. Duncan and C. Meghir (1998): "Estimating Labor Supply Responses Using Tax Reforms," Econometrica, 66, 827-861. 
Blundell, R.W., V. Fry and C. Meghir (1990): "Preference Restrictions in Microeconometric Models of Life Cycle Behaviour," Chapter 2 in Microeconometrics: Surveys and Applications, J.P. Florens, M. Ivaldi, J.J. Laffont and F. Laisney (eds.), Basil Blackwell, Oxford.

Blundell, R.W, C. Meghir and P. Neves (1993): "Labour supply and intertemporal substitution," Journal of Econometrics, 59, 137-160.

Blundell, R.W, P.-A. Chiappori, T. Magnac and C. Meghir (2005): "Collective Labour Supply: Heterogeneity and Nonparticipation," IZA Discussion Paper 1785.

Bover, O. (1986): "Some Dynamic Life Cycle Models of Labour Supply Estimated From Panel Data," Oxford Applied Economics Discussion Papers, 13.

Bover, O. (1989): "Estimating Intertemporal Labour Supply Elasticities Using Structural Models," Economic Journal, 99, 1026-1039.

Bover, O. (1991): "Relaxing Intertemporal Seperability: A Rational Habits Moel of Labour Supply Estimated from Panel Data," Journal of Labour Economics, 9, 85-100.

Browning, M. (1986): "The costs of using Frisch demand functions that are additive in the marginal utility of expenditure," Economics Letters, 21(3), 205-207.

Browning, M. and C. Meghir, (1991): "The Effects of Labour Supply on Commodity Demands," Econometrica, 59, 925-952.

Browning, M., A. Deaton and M. Irish (1985): “A Profitable Approach to Econometric Approaches to Labor Supply and Commodity Demands over the Life Cycle," Econometrica, 53, 503-543.

Camerer, C., L. Babcok, G. Loewenstein and R. Thaler, 1997, "Labor Supply of New York City Cabdrivers: One Day at a Time," Quaterly Journal of Economics, 112, 407-441.

Card, D. (1987): "Supply and Demand in the Labor Market," Princeton University Industrial Relations Section, Working Paper No. 228.

Card, D. (1994): "Intertemporal Labor Supply: an Assessment", in Advances in Econometrics, Sixth World Congress, C. Sims (ed.), Cambridge University Press, New York.

Chamberlain, G. (1984): "Panel Data," Chapter 22 in Handbook of Econometrics, Vol II, Z. Griliches and M.D. Intriligator (eds.), North-Holland, Amsterdam.

Conway, K. S. and T. J. Kniesner (1994): "Estimating labor supply with panel data," Economics letters, 44, 27-33.

Dustmann C. and M. E. Rochina-Barrachina (2000): "Selection correction in panel data models: an application to labour supply and wages," IZA Discussion Paper 162.

Eckstein, Z. and K.I. Wolpin (1989): "Dynamic Labour Force Participation of Married Women and Endogenous Work Experience," Review of Economic Studies, 56, 375-390.

Farber, Henry S. (2005): "Is Tomorrow Another Day? The Labor Supply of New York City Cabdrivers," Journal of Political Economy, 119, 46-82.

Fehr, E. and L. Götte (2007): "Do Workers Work More When Wages are High", American Economic Review, 97(1), 298-317.

Greene, W.H. (2004): "Fixed Effects and the Incidental Parameters Problem in the Tobit Model," Econometric Reviews, 23(2), 125-148.

Ham, J.C. (1986): "Testing Whether Unemployment Represents Intertemporal Labour Supply Behaviour," Review of Economic Studies, 53(4), 559-578.

Hansen, L. P. and J. S. Singleton (1982): "Generalized Instrumental Variables Estimation of Nonlinear Rational Expectations Models," Econometrica, 50, 1269-1286.

Heckman, J.J. (1981): "The Incidental Parameters Problem and the Problem of initial Conditions in Estimating a Discrete Time - Discrete Data Stochastic Process and Some Monte-Carlo Evidence," in Structural Analysis of Discrete Data, C. Manski and D. McFadden, (eds.), MIT Press, Cambridge, MA, 179-195.

Heckman, J.J. and T.E. MaCurdy (1980): “A Life Cycle Model of Female Labour Supply,” Review of Economic Studies, 47, 47-74.

Heckman, J.J. and T.E. MaCurdy (1982): "Corrigendum on A Life Cycle Model of Female Labour Supply," Review of Economic Studies, 49, 659-660.

Heckman, J.J. and T.E. MaCurdy (1986): "Labor Econometrics," Chapter 32 in Handbook of Econometrics, Vol III, Z. Griliches and M.D. Intriligator (eds.), North-Holland, Amsterdam. 
Henley, A. (2004): "House Price Shocks, Windfall Gains and Hours of Work: British Evidence", Oxford Bulletin of Economics and Statistics, 66(4), 439-456.

Holtz-Eakin, D., W. Newey and H.S. Rosen (1988): "Estimating Vector Autoregressions with Panel Data," Econometrica, 56, 1371-1395.

Hotz, V.J., F.E. Kydland and G.L. Sedlacek (1988): "Intertemporal Preferences and Labour Supply," Econometrica, 335-360.

Imai, S. and M. P. Keane (2004): "Intertemporal Labor Supply and Human Capital Accumulation.," International Economic Review, 45(2), 601-641.

Jakubson, G. (1988): "The Sensitivity of Labor Supply Parameter Estimates to Unobserved Individual Effects: Fixed- and Random-Effects Estimates in a Nonlinear Model Using Panel Data," Journal of Labor Economics, 6(3), 302-329.

Johnson, T.R. and J.H. Pencavel (1984): "Dynamic Hours of Work Functions for Husbands, Wives and Single Females," Econometrica, 52, 363-389.

Joulfaian, D. and M. O. Wilhelm (1994): "Inheritance and Labor Supply," Journal of Human Resources, 29, 1205-1234.

Killingsworth, M.R. (1983): Labor Supply, Cambridge University Press, Cambridge.

Killingsworth, M.R. and J.J. Heckman (1986): "Female Labor Supply: A Survey," Chhapter 2 in Handbook of Labor Economics, Vol I, O. Ashenfelter and R. Layard, (eds.), North-Holland, Amsterdam.

Laisney, F., M. Lechner, A. van Soest and G. Wagenhals (1993): "A Life Cycle Labour Supply Model with Taxes Estimated on German Panel Data : The Case of Parallel Preferences," Economic and Social Review, 24, 335-368.

Lich-Tyler, S. (2002): "Life-cycle labor supply under uncertainty," presented at the 2002 North American Econometric Society Winter Meeting.

Lilja, R. (1986): Econometric Analyses of Family Labour Supply over the Life Cycle Using US Panel Data, The Helsinki School of Economics, Helsinki.

Lundberg, S.J. (1988): "Labor Supply of Husbands and Wives: A Simultaneous Equations Approach," Review of Economics and Statistics, 70(2), 224-235.

MaCurdy, T.E. (1981): “An Empirical Model of Labor Supply in a Life-Cycle Setting,” Journal of Political Economy, 89, 1059-1085.

MaCurdy, T.E. (1983): "A Simple Scheme for Estimating an Intertemporal Model of Labor Supply and Consumption in the Presence of Taxes and Uncertainty," International Economic Review, 24, 265-290.

MaCurdy, T.E. (1990): "Appraising Tests of the Intertemporal Substitution Hypothesis," in Panel Data and Labour Market Studies, J. Hartog, G. Ridder and J. Theeuwes (eds.), North Holland, Amsterdam.

MaCurdy, T.E., D. Green and H. Paarsch (1990): “Assessing Empirical Approaches for Analyzing Taxes and Labor Supply," Journal of Human Resources, 25, 413-490.

Mazzocco, M. (2007): "Household Intertemporal Behavior: a Collective Characterization and a Test of Commitment", Review of Economic Studies, 74(3), 857-895.

Mincer, J. (1962): "Labor Force Participation of Married Women: A Study of Labor Supply," Aspects of Labor Economics, NBER, Princeton University Press, Princeton, N.J., 63-97.

Mroz, T.A. (1987): "The Sensitivity of an Empirical Model of Married Women's Hours of Work to Economic and Statistical Assumptions," Econometrica, 55, 765-799.

Mundlak, Y. (1978): "On the Pooling of Time-Series and Cross-Section Data," Econometrica, 46, 69-85.

Newey, W.K., (1984): “A Method of Moments Interpretation of Sequential Estimators," Economics Letters, 14, 201-206.

Oettinger G. S. (1999): "An Empirical Analysis of the Daily Labor Supply of Stadium Vendors," Journal of Political Economy, 107, 360-392.

Pagan, A. (1984): "Econometric Issues in the Analysis of Regressions with Generated Regressors," International Economic Review, 25, 221-247.

Pencavel, J. (1986): "Labor Supply of Men: A Survey," in O. Ashenfelter and R. Layard (eds.), Handbook of Labor Economics, North-Holland, Amsterdam. 
Pistaferri, L. (2003): "Anticipated and unanticipated wage changes, wage risk and life cycle labor supply," Journal of Labor Economics, 21, 729-754.

Shaw, K. (1989): "Life Cycle Labor Supply with Human Capital Accumulation," International Economic Review, 30(2), 431-457.

Wooldridge, J. M. (1995), "Selection corrections for panel data models under conditional mean independence assumptions,"emph Journal of Econometrics, 68, 115-132.

Ziliak, J.P. and T.J. Kniesner (1999): "Estimating Life-Cycle Labor Supply Tax Effects," Journal of Political Economy, 107, 326-359. 